\title{
Das psicoses associadas a infecções no Brasil: 100 anos da contribuição psicopatológica de Antonio Austregésilo
}

On psychoses associated with infections in Brazil: 100 years of the psychopathological contribution by Antonio Austregésilo

\author{
Paulo Dalgalarrondo*1 \\ Mônica Jacques de Moraes*2 \\ Eloísa Helena Rubello Valler Celeri*3 \\ Amilton dos Santos Júnior*4
}

\begin{abstract}
No presente trabalho, analisa-se a contribuição do neurologista e neuropsiquiatra Antonio Austregésilo (1876-1960) para o estudo psicopatológico e sistematização das chamadas psicoses infecciosas, no Brasil. Baseando-se em Emil Kraepelin e lançando mão de observações clínicas em doenças infecciosas globais e tropicais, Austregésilo revela detalhado conhecimento clínico e intervém no debate sobre etiologia, especificidades de fatores causais e curso da doença, na fronteira entre as doenças físicas infecciosas e os transtornos mentais.
\end{abstract}

Palavras-chave: Psicopatologia, psicoses infecciosas, neurologia, delírio, causalidade 


\section{ARTIGOS}

\section{Introdução}

Desde dezembro de 2019, uma nova pandemia assola a humanidade, a COVID-19, doença causada pelo novo coronavírus SARS-CoV-2. Logo se notou que pacientes com tal doença podem apresentar quadros psicopatológicos, como delirium, insônia, ansiedade, humor depressivo, irritabilidade, prejuízos da memória e estresse pós-traumático (Rogers et al., 2020). No entanto, ainda não está claro se os quadros psicopatológicos são consequência da infecção viral e sua repercussão encefálica, do sofrimento emocional e estresse relacionados à pandemia, ou de fatores do tratamento, como longa permanência em unidades de terapia intensiva e separação de familiares.

As relações entre doenças infecciosas e psicopatologia são conhecidas desde os inícios da psiquiatria, nos séculos XVIII e XIX. Os psiquiatras e psicopatólogos não deixaram de notar tal relação (Munjal et al., 2017). No Brasil, na história da psicopatologia que aqui se desenvolveu, tais temas e debates tiveram sua relevância. Trazemos aqui um caso exemplar, através de obra de um produtivo neurologista e neuropsiquiatra brasileiro, Antonio Austregésilo, produzida há um século em nosso país.

\section{Doenças infecciosas produzindo alienação mental: alguns termos psicopatológicos relacionados às psicoses infecciosas}

O presente artigo visa analisar, na obra de Antonio Austregésilo, o trabalho intitulado Psicoses inficiosas nas doenças tropicaes, de 1919. Para tanto, faz-se necessário examinar historicamente alguns construtos médicos e psicopatológicos relacionados à inter-relação entre condições e doenças físicas e transtornos mentais. Apenas o 
exame cuidadoso da história interna e conceitual de aspectos específicos da tradição médica e psicopatológica permite que se compreenda o texto de Austregésilo, impregnado pelos conceitos e debates situados no início do século XX.

Segundo Paul Bercherie (1989), na transição do século XVIII para o XIX, Philippe Pinel (1745-1826) considerava a distinção entre afecções com e sem febre como elemento de grande importância em sua taxonomia, possivelmente influenciado pela contraposição mania versus phrenitis da tradição hipocrática e galênica. Étienne-Jean Georget (1795-1828), no início do século XIX, propõe dividir os transtornos mentais em um grupo cujas causas são morais (ou seja, psicológicas, psicossociais, nos termos atuais) ou físicas (somáticas ou orgânicas). Estas últimas produziriam tipicamente o delírio agudo (délire aigüe), um tipo de afecção simpática, ou seja, a alteração física repercutiria sobre o cérebro, perturbando-o e produzindo a anormalidade mental. Assim, a noção de alienações sintomáticas ou simpáticas de Georget (mas usadas também por Bayle, Baillarger, Guislain e Griesinger) irá ocupar o lugar nosológico da phrenitis hipocrática.

Os termos delírio e delirium têm um uso variado e muitas vezes dúbio 648 ou repleto de ambiguidades na tradição médica e psicopatológica, nos últimos dois séculos. Por delirium, de modo geral, se denomina, desde o século XIX, quadros agudos de natureza orgânica, como o delirium febril, que se relaciona a qualquer quadro febril agudo produzindo clinicamente perturbação da atenção, do nível de consciência, obnubilação do sensório, desorientação, pensamento confuso (e apenas em alguns casos presença de ideias delirantes), ilusões e alucinações, quase sempre visuais, e estado afetivo de angústia, excitação ou pavor. Delirium é assim o termo herdeiro e transformação moderna (a partir do século XIX) da antiga phrenitis da medicina grega hipocrática e romana galênica (Berrios, 1996).

Já o termo delírio tem um uso, nos tratados e manuais de psiquiatria, desde o século XIX, consideravelmente variado, conforme o contexto de que se esteja tratando. Como esclarece Berrios (1996), nas tradições germânicas e britânicas a confusão terminológica, embora também presente, não foi tão grave, pois seus idiomas dispõem de termos claramente distintos para designar delírio (ideia delirante) e delirium (uma síndrome confusional orgânica e aguda); no alemão Wahn sempre designou ideia delirante ou loucura em geral e Delir ou Verwirrtheit, o delirium orgânico, agudo e frequentemente febril. No inglês, o termo delusion indica, desde há muito, ideia delirante e delirium, o quadro orgânico. Nas tradições alienistas de 


\section{ARTIGOS}

línguas latinas como a francesa, a confusão terminológica parece ser mais acentuada. Na França, o termo délire, desde o século XIX até há poucas décadas, refere-se tanto a um sintoma psicótico (ideia delirante), à loucura ou insanidade em geral e ao delirium. No ambiente francofônico designava-se o delirium por délire aigüe ou délire febrile (mas às vezes usava-se apenas o termo délire); já para se indicar psicose em geral (alienação ou insanidade mental), lançava-se mão de délire chronique sans fiévre (Berrios, 1996).

No português e no espanhol, têm-se as mesmas dificuldades que no francês. Delírio, no século XIX e primeira metade do XX, é frequentemente usado como sinônimo de delirium orgânico, febril, mas também é empregado com o sentido de ideia delirante, ou seja, um juízo falso produzido por um quadro psicótico (um delírio de perseguição, por exemplo), seja associado à esquizofrenia, a outra psicose, a quadros orgânicos ou psicogênicos. Finalmente, com certa frequência, sobretudo em textos do século XIX, como ocorria na França, delírio foi usado como sinônimo de alienação mental, psicose ou doença mental grave que perturba globalmente as funções mentais, sobretudo a esfera ideativa. De modo geral, no artigo de Austregésilo que examinaremos a seguir é utilizado o termo delírio com o sentido de delírio agudo (délire aigüe dos franceses) ou delirium e não com o sentido de ideia delirante.

\section{Dados biográficos e produção intelectual de Antonio Austregésilo}

Antonio Austregésilo Rodrigues Lima nasceu em Recife em 21 de abril de 1876 e faleceu no Rio de Janeiro em 23 de dezembro de 1960. Em Recife, estudou no Colégio das Artes, tendo contato com Tobias Barreto e o movimento literário e artístico com influências germanizantes da chamada Escola de Recife.

Estudou medicina no Rio de Janeiro e, em 1899, diplomou-se com a tese Estudo clínico do delírio, revelando já no início da carreira seu especial interesse pela psicopatologia. Apesar de filho de um advogado de Recife, Austregésilo é descrito por alguns biógrafos como de origem humilde, de pele parda, tendo tido tiques na infância e tartamudez durante toda a vida (Teive et al., 1999).

Nos primeiros anos de prática médica, foi interno da colônia de doentes mentais da Ilha do Governador e do Hospício Nacional de Alienados, no Rio de Janeiro. Em 1902, tornou-se médico da Santa Casa de Misericórdia do 
Rio de Janeiro. Entre 1902 e 1906, participou da equipe de Juliano Moreira, designada pelo presidente da República, Rodrigues Alves, para remodelar a Assistência aos Alienados. Entre 1904 e 1909, teve atuação intensa no Hospício Nacional de Alienados (Austregésilo, 1949). Assim, o neurologista, ao longo de sua vida, teve importante envolvimento com a psiquiatria e a psicopatologia, por isso talvez seja correto classificá-lo também como neuropsiquiatra (Leme Lopes, 1961; Neves-Manta, 1979).

Fez, nesse período, várias tentativas de entrar na carreira acadêmica como professor da Faculdade de Medicina do Rio de Janeiro, através de concursos, tendo sido preterido por três vezes. Entre os fatores de tal insucesso, sugeridos por biógrafos, teriam sido sua pele parda, a origem humilde, vindo do Nordeste do Brasil, e a sua situação econômica e social, ou seja, um membro da classe média, não pertencente às elites (Teive et al., 1999). Mas é difícil afirmar o quanto isso faz parte de uma certa idealização $a$ posteriori, a construção do mestre-herói.

Em 1912, foi indicado pela congregação da Faculdade de Medicina do Rio de Janeiro para a primeira cátedra de clínica neurológica e, em tal cátedra, teria fundado a primeira escola de neurologia no Brasil (Mota Gomes, 1999).

Além de médico voltado especialmente à neurologia clínica e à psiquiatria, também foi escritor, tendo produzido prosa e poesia, com obras suas publicadas em revistas simbolistas da época. Foi eleito, em 1914, membro da Academia Brasileira de Letras, tendo sido também membro da Academia Brasileira de Medicina (Gomes, 1999).

Sua produção médica, além da neurologia, abarca a psicopatologia (como no artigo discutido a seguir), vários estudos e livros sobre neuroses, "problemas nervosos", psicoterapia e higiene mental. Formulou uma doutrina de fames, libido e ego, ${ }^{1}$ para alicerçar sua proposta psicoterapêutica, aproximando-se, a seu modo, de construtos freudianos. Ele atribuía importância central tanto para os impulsos sexuais quanto para impulsos relacionados à sobrevivência.

${ }^{1}$ O livro Fames, Libido, Ego em sua tradução para o espanhol, de 1941 (Dr. A. Austregésilo. Buenos Aires: Nocito y Rañó, 1941. 155 pp.) foi revisto por certo(a) B. D. L. (só constam as iniciais), publicado em The Psychoanalytic Quarterly, 12, 408-409, 1943. O termo Fames é a versão latina da palavra fome, indicando que para Austregésilo, em analogia com o termo freudiano libido, as necessidades básicas nutritivas teriam uma participação significativa no psiquismo. Segundo essa resenha, considera-se a obra psicoterapêutica de Austregésilo inspirada em escritos freudianos iniciais, em popularizadores freudianos e autores "quase-freudianos". 


\section{ARTIGOS}

Conhecido por sua habilidade clínica, tornou-se famoso tanto pela erudição clínica, como pelo gosto e habilidade em ensinar e formar gerações de médicos e especialistas. Inquieto intelectualmente, escreveu muito, livros de neurologia, psiquiatria, e clínica médica, assim como obras de divulgação sobre sexologia (Uchôa, 1981).

Em 1916, lançou o conceito de catafrenia, designando um enfraquecimento adquirido das faculdades mentais, de início semelhante às demências, mas que, ao contrário das demências, pode melhorar e inclusive curar (Austregésilo, 1949).

As principais publicações internacionais de Austregésilo foram feitas em língua francesa, no início do século XX. ${ }^{2}$ Assim, sua contribuição internacional para a neurologia clínica é bastante significativa para um autor brasileiro, em um ambiente acadêmico com modesta tradição científica. Ele cita com frequência Kraft-Ebing, Freud, Charcot, Janet, Kraepelin. Assim, a obra de Austregésilo transita de forma ampla entre a neurologia clínica, a psicopatologia, a psicoterapia e certo tipo de psicologia popular e higiene mental, algo não incomum em autores do campo neurológico-psiquiátrico daquele momento. Na Tabela 1, listamos algumas das principais obras de Austregésilo, em ordem cronológica, com breve comentário. Antonio Austregésilo Rodrigues Lima, falece no Rio de Janeiro em 23 de dezembro de 1960, aos 84 anos de idade.

${ }^{2}$ São elas: Les reflexes pendulaires et pseudo-pendulaires. Revue Neurologique, 1927; Tumeur du plexus choroide. Revue Neurologique, 1927; Contribution brésilienne à l'etude de la sclérose amyotrophique. Revue Neurologique, 1930; Le petit cérébellisme. Revue Sud-Américaine de Médecine et de Chirurgie, 1930; Les chorées et les manifestations choréiformes. Revue Neurologique, 1930; Conception clinique des neuronoses et des neuromyéloses. L'Encephale, 1938; Aphasie et lobe parietal gauche. Presse Medicale, 1940; La fréquence de la sclerose em plaques au Brésil. Revue Neurologique, 1942; Myéloses seniles. Revue Neurologique, 1948 (Teive et al., 1999). 
Tabela 1: Principais Obras de Antonio Austregésilo Rodrigues Lima (1876-1960)

\begin{tabular}{|c|c|c|}
\hline Ano & Título & Comentários \\
\hline 1898 & Manchas & Livro de prosa poética. \\
\hline 1909 & Estudo clínico do delírio & $\begin{array}{l}\text { Publicação de sua Tese de doutoramento, de 1899. Também publica } \\
\text { Ataques epiléticos produzidos pelo brometo de cânfora. }\end{array}$ \\
\hline 1916 & Conceito de Catafrenia. & $\begin{array}{l}\text { Lança o construto catafrenia indicando enfraquecimento mental } \\
\text { adquirido e reversível, distinto da demência e de boa evolução. }\end{array}$ \\
\hline 1917 & $\begin{array}{l}\text { Clínica neurológica } \\
\text { (em três volumes; } \\
\text { 1917, 1934, 1945) }\end{array}$ & $\begin{array}{l}\text { Capítulos sobre diagnóstico de tabes, debilidade nervosa, cenestopatias, } \\
\text { polineurites escorbúticas, fenômeno de Babinski, tiques, síndrome } \\
\text { histeróide, ataques epileptóides. }\end{array}$ \\
\hline 1917 & Clínica médica & $\begin{array}{l}\text { Sobre semiologia médica, com fotos relacionadas a sinais físicos } \\
\text { patológicos e cortes histopatológicos. }\end{array}$ \\
\hline 1919 & $\begin{array}{l}\text { Psiconeuroses e } \\
\text { sexualidade }\end{array}$ & $\begin{array}{l}\text { Sobre neurastenia sexual e seu tratamento. Defende a tese de "quem } \\
\text { possui vida sexual normal não sofre dos nervos". O tratamento } \\
\text { fundamental é a psicoterapia (como reeducação da vontade). }\end{array}$ \\
\hline 1927 & $\begin{array}{l}\text { Troubles nerveux et } \\
\text { mentaux dans les } \\
\text { maladies tropicales }\end{array}$ & Conteúdo relacionado ao tema do texto discutido neste trabalho. \\
\hline 1936 & $\begin{array}{l}\text { L'analyse mentale } \\
\text { em pratique medicale }\end{array}$ & Livro editado pela editora francesa, Masson. \\
\hline 1938 & $\begin{array}{l}\text { Fames, libido, ego. } \\
\text { Perfil da mulher } \\
\text { brasileira. }\end{array}$ & $\begin{array}{l}\text { Perfil da mulher é obra dentro do grupo de estudos sobre psicologia } \\
\text { popular. }\end{array}$ \\
\hline 1939 & $\begin{array}{l}\text { O mal da vida; } \\
\text { Conduta Sexual e } \\
\text { As Psiconeuroses. }\end{array}$ & $\begin{array}{l}\text { Série de ensaios sobre psicoterapia, traz capítulos sobre insatisfação, } \\
\text { conceito de felicidade, pessimismo, otimismo, estoicismo, articulando } \\
\text { posições filosóficas e morais com uma proposta de psicoterapia. }\end{array}$ \\
\hline 1940 & $\begin{array}{l}\text { Manuel de } \\
\text { psychothérapie pratique. }\end{array}$ & $\begin{array}{l}\text { Editado por Masson, expõe sua técnica psicoterápica. Publica Pequenos } \\
\text { Males, Palavras Acadêmicas, Cura dos Nervosos, Conselho prático } \\
\text { para os nervosos, Viagem Interior. }\end{array}$ \\
\hline 1943 & Perfis de Loucos & Estudos psicológicos de casos de psicose, em tom literário. \\
\hline 1946 & Patologia Mental & Coletânea de suas principais obras psicopatológicas e psiquiátricas. \\
\hline 1950 & Vidas desgraçadas & Único romance escrito por Austregésilo \\
\hline 1951 & Psicologia e psicoterapia & Outra síntese de suas concepções psicoterápicas \\
\hline 1953 & Da biótica humana & $\begin{array}{l}\text { Ensaios visando integrar aspectos morais e biológicos sobre o } \\
\text { psiquismo humano e seus transtornos mais comuns. }\end{array}$ \\
\hline
\end{tabular}




\section{ARTIGOS}

\section{A obra Psicoses inficiosas nas doenças tropicaes}

Há pouco mais de um século, no primeiro volume e número dos Archivos Brasileiros de Neuriatria e Psychiatria, de 1919, Antonio Austregésilo (1919) publica Psicoses inficiosas nas doenças tropicaes (a grafia no artigo é inficiosas e tropicaes), disposto a rever o que se sabe internacionalmente e o que sua experiência clínica e a de seus colegas brasileiros ensinam sobre a relação entre doenças infecciosas, sobretudo as ditas tropicais, e os quadros psicopatológicos, sobretudo os mais graves.

$\mathrm{Na}$ primeira parte do artigo, o autor revê o conceito de psicoses infecciosas, baseando-se principalmente na clássica divisão de Kraepelin (1899), em três grandes grupos de afecções mentais associadas às infecções: delírios febris, delírios infecciosos e estados de enfraquecimento psíquico que ocorrem após a infecção. A tentativa de diferenciar entre o delírio febril e o infeccioso aparece de forma proeminente nesse trabalho de Austregésilo, algo também presente no debate internacional da época.

As doenças infecciosas mais frequentes, não restritas aos trópicos, revistas por ele são: gripe (influenza), febre reumática (eventualmente chamada por ele reumatismo articular), tuberculose e sífilis. Em relação às doenças tropicais, o autor examina detalhadamente as seguintes condições: impaludismo (malária), febre amarela, peste (ou peste bubônica), cólera morbus (cólera), lepra, beribéri (que Austregésilo não considera doença infecciosa, mas a inclui pois vários autores a consideravam assim), ancilostomíase e cisticercose.

A fim de permitir a interpretação do texto original de Austregésilo, nas tabelas $2 \mathrm{a}$ e $2 \mathrm{~b}$ abaixo, descrevem-se os nomes das doenças, sinonímias, aspectos históricos e o panorama dos conhecimentos científicos sobre cada doença em 1919, ano do artigo de Austregésilo 


\begin{tabular}{|c|c|c|c|c|}
\hline 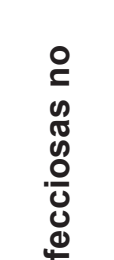 & 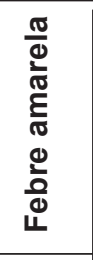 & 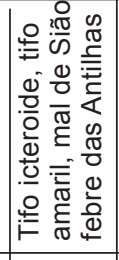 & 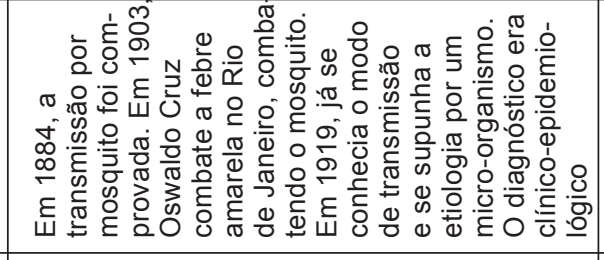 & 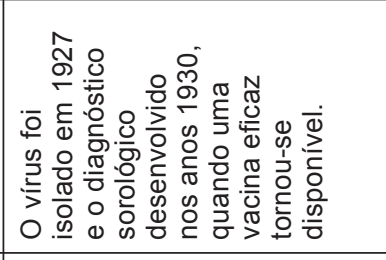 \\
\hline 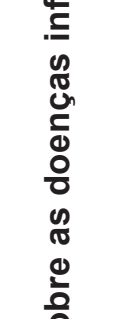 & 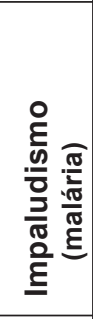 & 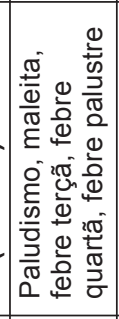 & 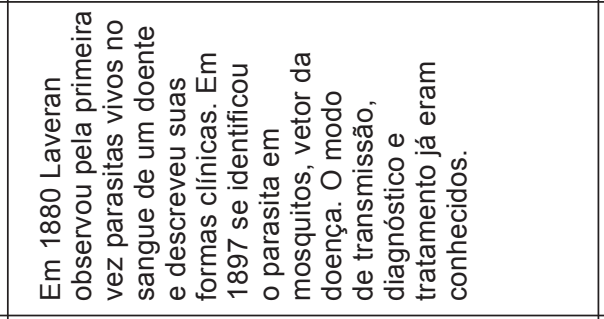 & 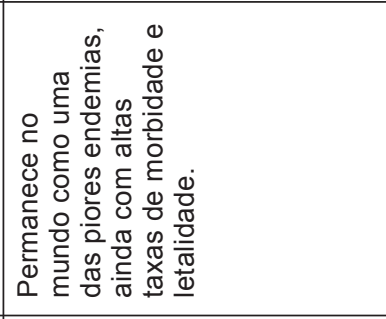 \\
\hline 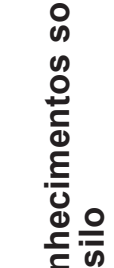 & 畩 & 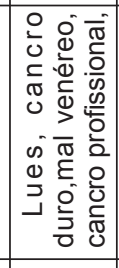 & 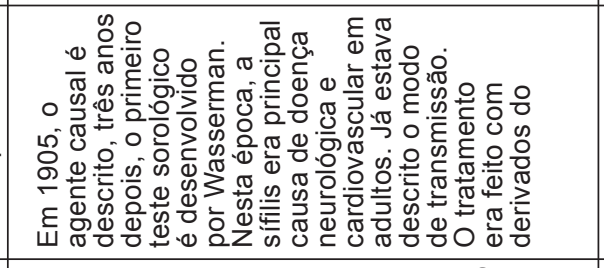 & 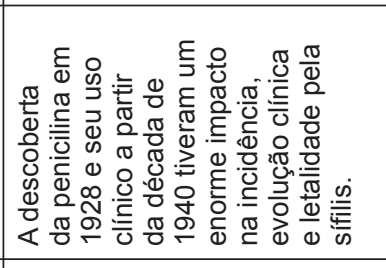 \\
\hline 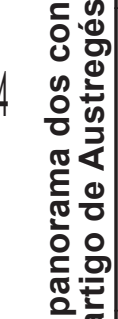 & 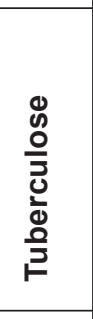 & 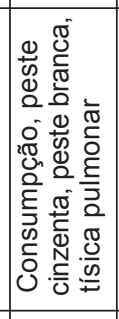 & 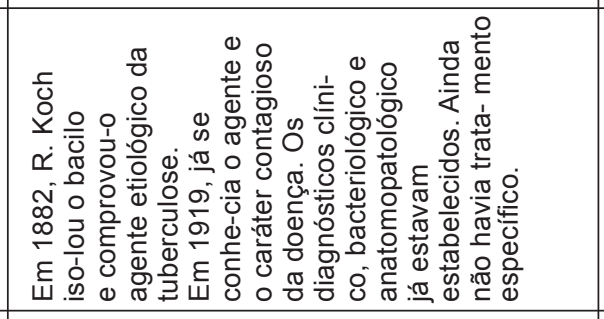 & 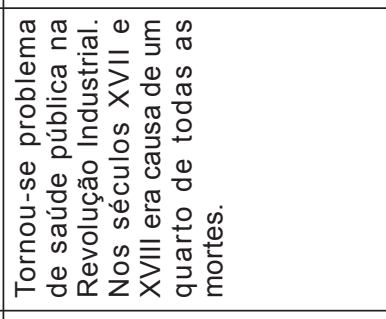 \\
\hline 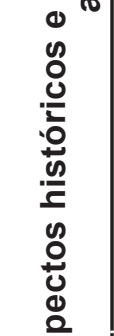 & 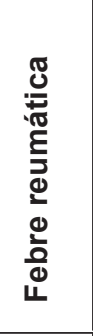 & 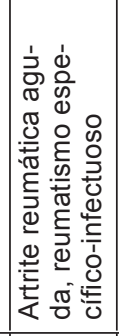 & 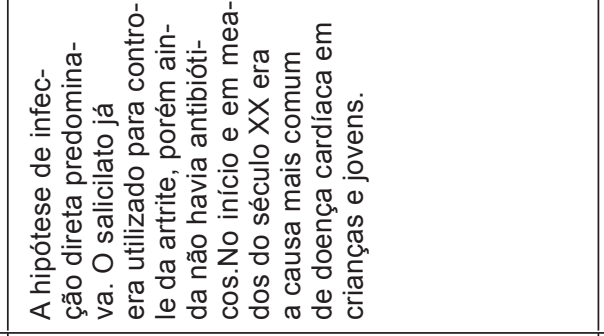 & 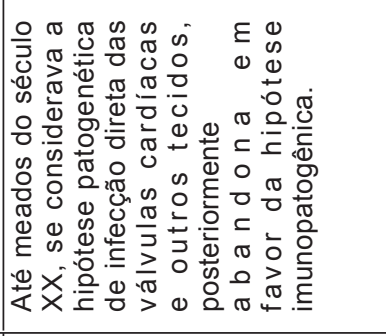 \\
\hline 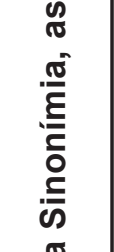 & 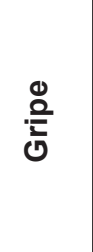 & 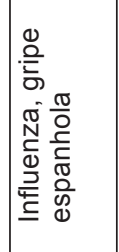 & 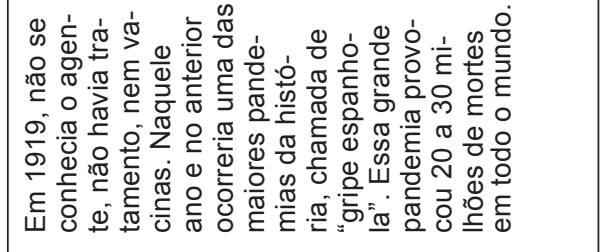 & 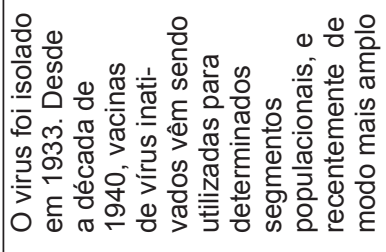 \\
\hline $\begin{array}{l}\frac{\pi}{0} \\
\frac{0}{0} \\
\frac{0}{10}\end{array}$ & & 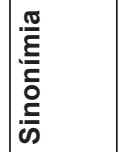 & 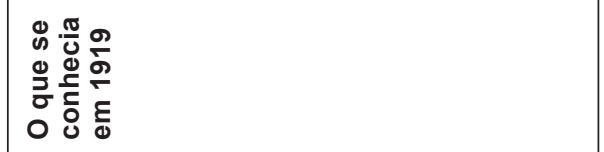 & $\frac{2}{20}$ \\
\hline
\end{tabular}




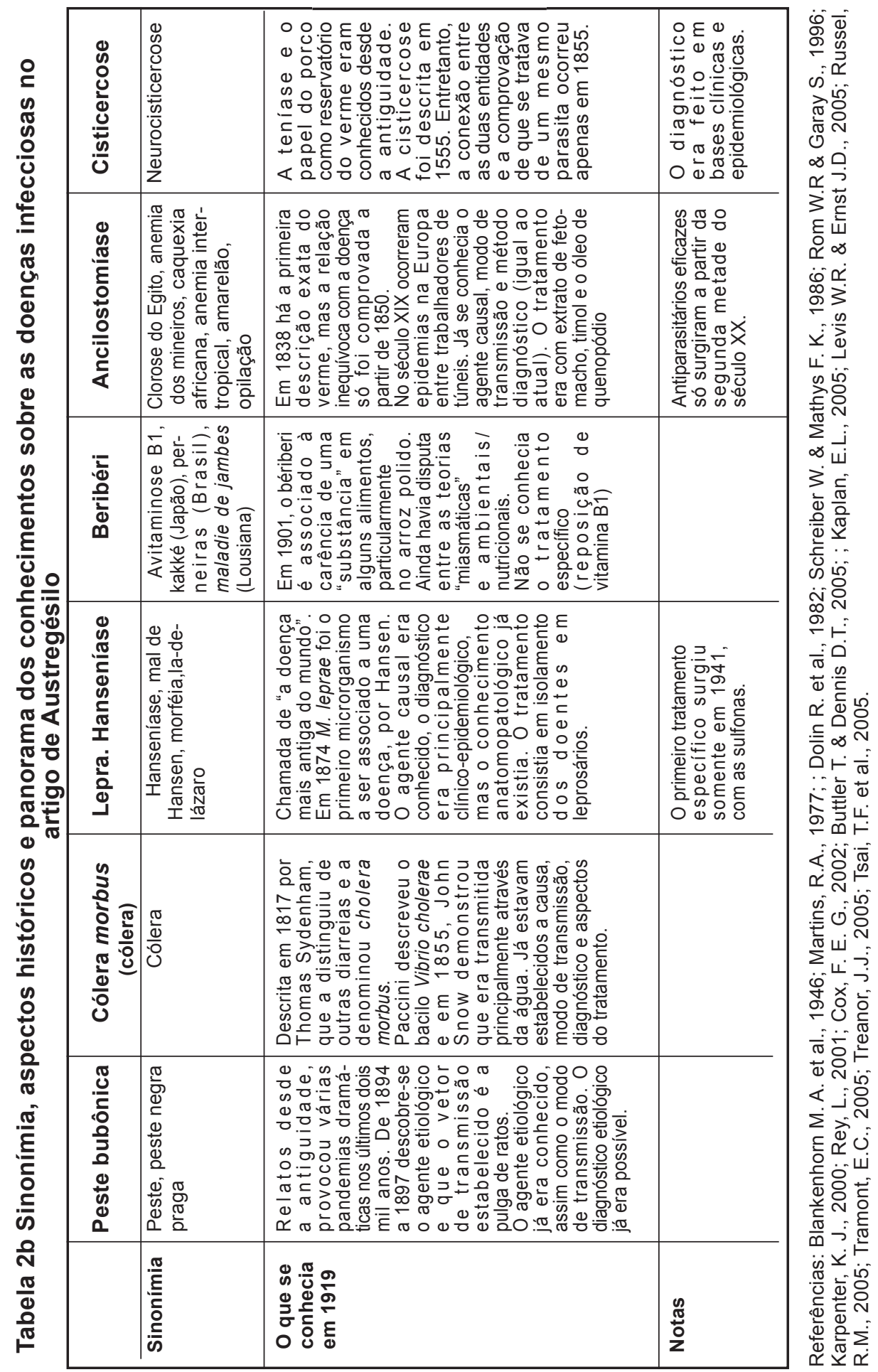


A pandemia de gripe ou influenza que chegou ao Brasil em outubro e novembro de 1918 havia deixado fortes impressões sobre os médicos em geral, assim como neurologistas e psiquiatras. Juliano Moreira, autor muito respeitado e citado repetidamente por Austregésilo, publicou um trabalho em maio de 1919, nos Archivos Brasileiros de Medicina, relatando desde quadros de simples obnubilação intelectual, até graves delírios com fuga e suicídios. Seguindo a visão de Kraepelin, Juliano Moreira teria confirmado que os quadros de delírios (no caso delirium) associados à influenza ocorrem antes, durante e após o período febril da infecção. Todo tipo de síndrome psicopatológica pode surgir na influenza, segundo opinião de Juliano Moreira. Também constata esse autor a não existência de dementia paralytica gripal, ou seja, a ocorrência da paralisia geral progressiva, tipicamente associada à sífilis, não se observaria na influenza. Passado o período agudo da gripe, seriam frequentes os quadros de enfraquecimento mental pós-infeccioso, na linha do sugerido por Kraepelin.

A febre reumática, denominada por Austregésilo como reumatismo articular poderia produzir delírios, como o delírio coreico. A coreia de Sydenham estaria associada a tais manifestações neuropsiquiátricas da febre 656 reumática.

A tuberculose, em especial a sua forma pulmonar, estaria frequentemente associada a perturbações mentais. Estas ocorreriam por conta da febre, das intoxicações, anemia e fraqueza crescente. Chama a atenção a atitude global do paciente, que apresentaria um psiquismo doloroso, diante do qual tudo desaparece, exceto a necessidade de viver. As meningites da tuberculose causariam também delírios agitados.

Já a sifilis, bem mais conhecida em seus aspectos neuropsiquiátricos (lembrar da famosa paralisia geral progressiva ou dementia paralytica, entidade símbolo no século XIX), tem um espaço especial no trabalho de Austregésilo. Nos períodos terciários e quaternários da sífilis ocorreriam mais frequentemente os quadros psicopatológicos. Estados depressivos, obnubilação intelectual, incoerência das ideias, assim como mudanças da personalidade e demência seriam comuns nas fases avançadas da sífilis. Cabe lembrar que Austregésilo cita o seu aforismo que se tornou clássico nas escolas médicas brasileiras, que afirma que para diagnosticar uma doença com sintomas tão múltiplos e, por vezes, não evidentes, é necessário pensar na doença, pensar em sua lógica sintomática, às vezes não facilmente perceptível. As duas grandes síndromes neuropsiquiátricas associadas à sífilis, a Tabes (ou tabes dorsalis) e a Paralisia Geral (ou PGP, paralisia geral progressiva) são lembradas pelo autor. 


\section{ARTIGOS}

Após rever essas doenças infecciosas graves, frequentes e presentes em todo o mundo, Austregésilo passa às doenças infecciosas tropicais, para examinar suas manifestações psiquiátricas. Inicia pela malária, denominada nesse momento impaludismo ou infecção palustre. $\mathrm{O}$ caráter febril marcante dessa doença relaciona-se claramente aos seus episódios agudos graves. Austregésilo distingue o delírio febril (delirium associado ao quadro febril), o delírio infeccioso (decorrente do quadro infeccioso geral) e o que denomina caquexia palustre, ou seja, um quadro de prejuízo da cognição, com regressão (infantilismo) do funcionamento psíquico do doente. Nesse caso, Austregésilo segue de perto Kraepelin, na sua divisão tripartite dos quadros psicopatológicos associados às doenças infecciosas.

Chama a atenção a preocupação com o diagnóstico laboratorial da malária, já em 1919. Austregésilo cita o exame de sangue em que podem ser reconhecidas as formas anulares e adultas do parasito de Laveran (ou seja, o plasmodium). Também é interessante a rejeição de Austregésilo pela hipótese de haver uma paralisia geral progressiva associada à malária, como formuladas por Régis e Bonet.

A febre amarela teria um lugar à parte na etiologia das psicoses, segundo o autor. Os quadros de delirium febril seriam relativamente frequentes, podendo ocorrer também a amentia (forma grave de delirium com intensa confusão mental e igualmente marcantes alucinações). Austregésilo cita o professor Márcio Nery, que teria classificado as perturbações mentais post-amarílicas, ou psicoses icteroides em quatro subgrupos, de acordo com o padrão de manifestação psicopatológico (estados de confusão, maníacos, melancólicos ou neuróticos). Austregésilo mantém aqui também a visão kraepeliniana de abordagem tripartite do delirium em febril, infeccioso e enfraquecimento pós-infeccioso.

A peste ou peste bubônica também poderia produzir quadros de perturbação do sensório (delirium), assim como, segundo o autor, delírios mansos, angustiosos, murmurantes, lúcidos ou furiosos. Também relata Austregésilo o estado de enfraquecimento pós-infeccioso em uma mocinha que foi acometida pela peste, apresentando um quadro de colorido melancólico. Em outros dois doentes com peste, o autor relata quadros de delirium febril, de amentia e de enfraquecimento pós-infeccioso. Cita aqui também o chamado delírio do colapso de Kraepelin.

Austregésilo reconhece que a cólera ou cólera morbus já não é tão frequente no contexto brasileiro. Suas manifestações neuropsiquiátricas seriam semelhantes ao de outras psicoses infecciosas. Pode ocorrer aqui também o 
quadro de amentia, e em alguns pacientes as formas graves de cólera produziriam torpor, delirium e coma.

A doença de Chagas, produzida pelo tripanossomo não é esquecida na revisão de Austregésilo. O parasito teria grande predileção pelo sistema nervoso central, diz ele. Seriam frequentemente associados à doença de Chagas quadros como a idiotia (ou seja, perturbação da cognição de início bem precoce na vida), o infantilismo e estados psicossomáticos semelhantes às encefalopatias da infância. $\mathrm{Na}$ fase aguda da doença, haveria um quadro febril, septicêmico, produzindo delirium infeccioso, meningoencefalite, meningites agudas e delirium de modo geral. Esta forma acometeria de maneira preferencial crianças. Já as formas crônicas determinariam estados psico-orgânicos crônicos, sem febre, produzindo quadros de idiotia e imbecilidade (ou seja, perturbação do desenvolvimento cognitivo da criança), assim como quadros propriamente neurológicos como afasias, síndromes bulbares e pseudobulbares, esclerose cerebral e paralisias motoras diversas. Finalmente, ainda discutindo a Doença de Chagas, Austregésilo enfatiza a dificuldade de estabelecer relações causais específicas; fala da importância do exame de sangue dos pacientes, assim como pela identificação epidemiológica da zona de habitação de onde provém o paciente.

O caso da lepra é mais controverso, sobre se ela produz ou não uma psicose infecciosa, afirma Austregésilo. Novamente ele recorre à opinião balizada de Juliano Moreira, que não admite uma psicose leprosa. Mas vários autores fazem referências a transtornos mentais associados à lepra. Outros alienistas brasileiros como Franco da Rocha fizeram observações clínicas de pacientes com lepra que apresentavam delírio de perseguição, depressão com estupor e mesmo a demência paralítica (classicamente associada à sífilis). O próprio Juliano Moreira, apesar de não admitir uma psicose específica da lepra, relata casos de pacientes com lepra com transtornos mentais (observação de Juliano Moreira citada por Kraepelin). Austregésilo descreve então um caso observado por ele mesmo de um paciente com lepra (com perda de falangetas, orelhas delgadas, ulceração do septo nasal e alterações dermatológicas próprias da lepra) que apresentou quadro de confusão mental, alucinações auditivas e visuais. Neste caso, Austregésilo diz que se viu obrigado a fazer o diagnóstico de psicose leprosa, o que o contrariou pelo fato clínico tê-lo obrigado a discordar de Juliano Moreira.

O caso do beribéri é bastante curioso. Hoje essa condição é conhecida como uma doença não infecciosa, mas causada pela carência específica da vitamina B1 (tiamina), que produz neuropatia, fraqueza muscular, 


\section{ARTIGOS}

cardiomegalia e em condições de carência extrema a encepalopatia de Wernicke (delirium e confusão mental, ataxia e oftalmoplegia e/ou nistagmo) e a síndrome de Korsakov (perda da memória recente, de fixação, desorientação temporal ou temporo-espacial e confabulações). Nos casos graves, a morte ocorre com relativa frequência.

Austregésilo resolve incluir o beribéri em sua revisão, pois apesar de discordar de sua etiologia infecciosa, vários autores assim o consideram. Muito atualizado, Austregésilo aponta para uma avitaminose, como o patologista Funk teria indicado. Para Austregésilo (1919): “a questão do beribéri não está resolvida. Como parece, a doença ataca com mais facilidade os pardieiros, as embarcações, os orfanatos, os quartéis, os colégios, isto é, as habitações coletivas, devemos pensar que a causa eficiente estará na alimentação contaminada por algum fungo" (p. 376). De fato, estudos posteriores demonstraram uma associação entre o arroz contaminado por fungos, a depleção de vitamina B1 nesse arroz contaminado e o beribéri. ${ }^{3}$

Epidemias de beribéri há haviam sido descritas no norte do Brasil, entre 1870 e 1910, analisadas por Josué de Castro em sua Geografia da fome, de 1946. Assim, a análise de Austregésilo considera o debate etiológico ainda bastante confuso em sua época, inclui fatores epidemiológicos relevantes como formas de agrupamentos humanos e suas consequentes condições de alimentação, cita a possibilidade de avitaminose (algo extremamente novo para a época) e uma associação entre contaminação do arroz por um fungo e suas possíveis consequências.

Ainda sobre o beribéri, o autor cita os trabalhos de Nina Rodrigues, Juliano Moreira e Afranio Peixoto. Nina Rodrigues cita a confusão mental dos beribéricos (possivelmente manifestação da encefalopatia de Wernicke), a amnésia (atualmente relacionada à síndrome de Korsakov). Austregésilo (1919) termina afirmando que para ele "todo beribérico tem perturbações mentais” (p. 377), algo corroborado atualmente, posto que a deficiência grave de tiamina se relaciona intimamente às duas síndromes (Wernicke e Korsakov) acima mencionadas.

${ }^{3}$ Nos anos de 2006 e 2007, nos estados do Maranhão e Tocantins, ocorreu um surto de beribéri (com 466 casos em 2006 e 543 casos em 2007, ocorrendo 33 mortes em 2006). Das causas supostas, a contaminação do arroz por fungos produtores de microtoxinas é apontada como a mais provável (Cabral de Lira \& Sousa de Andrade, 2008). 
A ancilostomose, doença símbolo da condição miserável do homem brasileiro rural do início do século XX, caracterizado pelo Jeca Tatu de Monteiro Lobato (Palma, 2003), infestado por ancilóstomos, anêmico, pobre, apático, indolente. As psicoses por helmintos, segundo Austregésilo, seriam raras, baseadas em um quadro de enfraquecimento do organismo (que ele chama de "fundo mioprágico"). As tênias, áscaris e oxiúros produziriam alterações mentais apenas em indivíduos com "forte tara neuropática", diz o autor ( $p$. 380). ${ }^{4}$ Nota-se aqui a presença de concepções da segunda metade do século XIX relativas à degeneração, a taras adquiridas que se tornam herdáveis, em uma forma de pensamento lamarckiano, comum no final do XIX e início do XX.

Finalmente, a última doença infecciosa tropical examinada por Austregésilo é a cisticercose. O famoso professor de medicina Miguel Couto já havia, junto com Austregésilo, descrito desordens mentais semelhantes a psicoses, depressões (semelhantes à lipemania, ou seja, aparentada à atual depressão), quadros de delirium, histeria ou epilepsia associados à neurocisticercose. $\mathrm{O}$ autor acredita que a patogenia da neurocisticercose seria mais tóxica do que compressiva (o cisticerco formando um cisto, calcificado ou não, comprimindo estruturas cerebrais). Hoje se pensa, no sentido oposto a 660 Austregésilo, que o fator patogênico mais importante seja a compressão.

\section{Psicoses infecciosas: surgimento e evolução do conceito}

Emil Kraepelin (1856-1926), na segunda edição de seu compêndio de Psiquiatria, de 1887, situa, após a melancolia e a mania, os quadros de delírio febril, delírio tóxico e delírio transitório. Na quinta edição do compêndio, de 1896, ele ordena os quadros agudos do delírio febril e do delírio tóxico em um grande capítulo destinado às intoxicações. É, entretanto, apenas na clássica sexta edição de seu tratado de Psiquiatria que ele decide dedicar um capítulo separado para a Loucura Infecciosa (Das infectiöse Irresein), subdividindo

${ }^{4}$ Não se nota nos textos de Austregésilo o debate médico-sociológico que se inicia, no Brasil, nas primeiras décadas do século XX, entre a posição pessimista sobre o Brasil e o povo brasileiro, mestiço e degenerado, e a visão sanitarista (inicialmente) e culturalista (a partir da década de 1930, com Gilberto Freyre), dos males do Brasil residindo nas condições de vida da população pobre, rural e urbana. Sua posição é, ao que parece, um intermédio, mesclando noções sobre constituição, degenerescência e de fatores exógenos, como alimentação, condições sanitárias e pobreza. 
os quadros clínicos respectivos em delírio febril, delírio infeccioso e enfraquecimento infeccioso. É esta forma de abordar as psicoses infecciosas que Austregésilo acaba por adotar para analisar os quadros de psicoses associadas à doenças infecciosas, sejam elas universais ou tropicais.

Assim, no segundo volume de seu Psychiatrie: Ein Lehrbuch für Studierende und Ärzte, de 1899, o primeiro capítulo é sobre as loucuras infecciosas. O capítulo é dividido em três partes: Die Fieberdelirien (os delirium febris), Die Infetiosdelirien (os delirium infecciosos) e Die infectiösen Schwächezustände (os quadros de debilitação infecciosos). É essa aproximação que irá marcar o trabalho de Austregésilo, desviando dela em apenas alguns momentos.

Por delirium febril Kraepelin toma todos os quadros agudos de confusão mental causados ou desencadeados pela febre. É a febre e não a infecção o fator mais importante. Ele diz: "O tipo especial de doença febril parece, no geral, influenciar pouco a forma do delirium. Apenas a velocidade pela qual a febre se desenvolve, a intensidade e duração da febre, assim como o estado dos órgãos vitais do organismo, o que determina o quadro [o delirium febril]". Assim, os fatores determinantes são a febre mesma (das Fieber selbst) e suas consequências como a elevação da temperatura, a aceleração do metabolismo e o surgimento de substâncias catabólicas especiais.

No caso do delirium infeccioso é a doença infecciosa e suas alterações sobre o organismo o fator mais importante. Kraepelin (1899), neste caso, acredita em substâncias tóxicas, venenosas, liberadas pelos agentes infecciosos, como o elemento etiológico mais importante. Ele fala repetidamente em Vergiftung (envenenamento, intoxicação). De fato, a ideia de que substâncias tóxicas ainda não bem conhecidas no final do século XIX seriam elementos-chave para compreender a etiologia e fisiopatologia não apenas do delirium infeccioso, mas também das psicoses endógenas (dementia praecox e a loucura maníaco-depressiva) era uma hipótese forte no pensamento kraepeliniano.

Finalmente, o terceiro tipo de loucura infecciosa, o mais heterogêneo dos três, seria o representado pelos estados de enfraquecimento e debilidade produzidos pela infecção. Neste item, Kraepelin inclui desde formas leves de cansaço, dificuldades para pensar, para ler, para escrever uma carta, sintomas depressivos e hipocondríacos vários, até quadros graves que evoluem para morte ou para estados demenciais. Em alguns casos, o estado confusional continua ou volta a aparecer depois de remitido no final da fase aguda da doença. Alguns doentes desenvolvem quadros semelhantes aos descritos por Sergey Sergeevich Korsakov (1854-1900) em 1887, em que além de polineurite, 
o paciente revela alterações da memória recente, fabulações e desorientação temporal. Mas Kraepelin reconhece, como pensava Korsakov, que em muitos dos pacientes que observara o fator infeccioso, este associa-se ao alcoolismo crônico para que tal quadro surja. Alguns pacientes também apresentam sinais da paralisia geral progressiva, mas o exame cuidadoso desses pacientes permite o diagnóstico diferencial, quando não se trata de neuro sífilis.

\section{Considerações finais}

O problema das relações causais em psicopatologia e a posição de Antonio Austregésilo

O trabalho de Antonio Austregésilo obriga à reflexão psicopatológica sobre relações causais e sobre especificidade de fatores causais para a determinação dos quadros psicopatológicos. Como visto anteriormente, o quadro clínico hoje denominado delirium têm uma longa história. Na Grécia antiga, os primeiros médicos denominavam phrenitis a formas de loucura associadas à febre e doenças claramente somáticas. A partir de finais do século XVIII e início do XIX essa grande síndrome vai receber nomes diversos como alienação sintomática, alienação simpática, delírio agudo e delírio febril.

A relação entre um quadro infeccioso, a possível implicação do cérebro nesse quadro infeccioso e a ocorrência de alterações psicopatológicas representa uma série de fenômenos clínicos e psicopatológicos de alta complexidade e múltiplas determinações. Infecções por microrganismos como o treponema pallidum da sífilis, o bacilo de Koch da tuberculose ou as diversas espécies de plasmódios da malária são agentes causais para doenças determinadas. $\mathrm{O}$ agente causal pode se relacionar com um quadro psicopatológico por ação direta no cérebro, por produzir alterações físicas no organismo com repercussões à distância no cérebro, ou por processos indiretos como febre, anemia, enfraquecimento global do organismo, assim como através de vivências psíquicas como medo do adoecimento, risco de morte e de sequelas da doença física. Enfim, a determinação de que fator pode ou não produzir um quadro psicopatológico é, hoje e na época do estudo de Austregésilo, portanto, de grande complexidade.

Além disso, deve-se ter em conta que até meados do século XX certas entidades nosológicas, como exemplo, a Paralisia Geral Progressiva e a Tabes dorsalis, existiam quase como entidades autônomas em relação às doenças infecciosas que com maior frequência as determinava (no caso a sífilis do sistema nervoso). 


\section{ARTIGOS}

A preocupação com a relação causal é bastante central no texto de Austregésilo, ora evidente, ora nas entrelinhas. Na página 380, quando discute a ancilostomíase, ele diz: "Nas três observações citadas, a ancilostomíase pareceu-nos a causa próxima dos desvios mentais. Provava-o em primeiro lugar a evolução da moléstia: ao mesmo tempo que diminuíam os sintomas ordinários da infestação, apagavam-se as alterações psíquicas. O paralelismo foi tão evidente que se diria esquemático."

O próprio Kraepelin, como mencionado anteriormente, questionava a precisão da relação causa-efeito no capítulo das psicoses infecciosas. $\mathrm{Na}$ página 14 de seu tratado ele diz: "[...] o delirium febril talvez deva ser visto apenas como uma forma especial do delírio infeccioso". Fatores como febre, debilitação global do organismo, possíveis toxinas liberadas pelo quadro infeccioso, devem atuar em maior ou menor grau, afetando o cérebro e o psiquismo. Estes últimos não são também semelhantes em todos os indivíduos acometidos. Predisposições individuais devem também exercer o seu papel.

Em toda sua discussão contrapondo delírio febril e delírio infeccioso, Kraepelin deixa claro que a distinção é extremamente precária, visão também compartilhada por Austregésilo. Não sabiam (e ainda não sabemos) quais fatores específicos e quais fatores gerais são os mais intimamente relacionados a muitos quadros mentais agudos vistos em doenças infecciosas. $\mathrm{O}$ raciocínio clínico, o conjunto de dados científicos disponíveis e a observação empírica demonstram que esses primeiros clínicos das ciências neurológicas e psicopatológicas no Brasil eram muito menos ingênuos do que muitas vezes certa historiografia, marcada por anacronismos e preconceitos, faz supor.

\section{Referências}

Austregésilo, R. L. A. (1919). Psicoses infeciosas nas doenças tropicaes. Archivos Brasileiros de Neuriatria e Psychiatria, ano I, 1(1), 351-383.

Austregésilo, R. L. A. (1949). Catafrenias. In Patologia Mental (pp. 47-69). Rio de Janeiro, RJ: Guanabara.

B. D. L. (1943). Fames, libido, ego. The Psychoanalytic Quarterly, 12, 408-409.

Bercherie, P. (1989). Os fundamentos da clínica: história e estrutura do saber psiquiátrico. Rio de Janeiro, RJ: Jorge Zahar.

Berrios, G. E. (1996). Consciousness and its disorders. In The history of mental symptoms: Descriptive psychopathology since the nineteenth century. (pp. 229-259). Cambridge, UK: Cambridge University Press. 
Blankenhorn, M. A., Vilter, C. F., Scheinker, I. M., \& Austin, R. S. (1946). Occidental Beriberi Heart Disease. J Am Med Assoc., 131(9), 717-726.

Buttler, T., \& Dennis, D. T. (2005). Yersinia Species (Including Plague). In Gerald, L., Mandell, R., Gordon Douglas, Jr., \& John E. Bennett (Eds.), Principles and practice of infectious diseases ( $6^{\text {th }}$ ed., pp. 2691-2701). Elsevier Churchill Livingstone.

Cabral de Lira, P. I., \& Sousa de Andrade, S. L. L. (2008). Epidemia de beribéri no Maranhão, Brasil. Cadernos de Saúde Pública, 24(6), 1202-1203.

Cox, F. E. G. (2002). History of Human Parasitology. Clin. Microbiol. Rev., 15, 595-612.

Dolin, R., Reichman, R. C., Madore, H. P., Maynard, R., Linton, P. N., \& WebberJones J. (1982). A controlled trial of amantadine and rimantadine in the prophylaxis of influenza A infection. $N$ Engl J Med., 307(10), 580-584.

Gomes, M. M. (1999). Vultos da história da neurologia no Rio de Janeiro. In R. Reimão (Org.), História da Neurologia no Brasil. São Paulo, SP: Lemos Editorial.

Kaplan, E. L. (2005). Reumatic Fever. In Kasper D. L. et al. (Eds.), Harrison's principles of Internal medicine (16 ${ }^{\text {ed. }}$, pp. 1977-1979). New York, NY: McGraw-Hill.

Karpenter, K. J. (2000). Beriberi, white rice, and vitamin B: a disease, a cause, and a cure. Berkeley (CA): University of California Press.

664 Kraepelin, E. (1899). Psychiatrie: Ein Lehrbuch für Studierende und Aerzte. II Band. Leipzig, GER: Verlag Von Johann Ambrosium Barth.

Leme Lopes, J. (1961). Antônio Austregésilo, psiquiatra. Jornal Brasileiro de Psiquiatria, 2, 109-161.

Levis, W. R., \& Ernst, J. D. (2005). Mycobacterium leprae (leprosy, Hansen's Disease). In L. Gerald, R. Mandell, D. Gordon Jr., \& John E. Bennett (Eds.), Principles and practice of infectious diseases (6 ${ }^{\text {th }}$ ed., pp. 2886-2896). London, UK: Elsevier Churchill Livingstone.

Martins, R. A. (1977). Contágio: história da prevenção das doenças transmissíveis. São Paulo, SP: Moderna.

Mota Gomes, M. (1999). Vultos da história da neurologia no Rio de Janeiro. In R. Reimão (Org.), História da neurologia no Brasil. São Paulo, SP: Lemos Editorial.

Munjal, S., Ferrando, S. J., \& Freyberg, Z., (2017). Neuropsychiatric Aspects of Infectious Diseases: An Update. Crit Care Clin. 33(3), 681-712.

Neves-Manta, I. L. (1979). A psiquiatria na obra de Austregésilo. Recife, PE: Livraria São José.

Palma, A. (2003). Monteiro Lobato e a gênese do Jeca Tatu. Fio da História. São Paulo, SP: Editora SENAC.

Rey, L. (2001). Um século de experiência no controle da ancilostomíase. Revista da Sociedade Brasileira de Medicina Tropical, 34(1), 61-67. 


\section{ARTIGOS}

Rogers, J. P., Chesney, E., Oliver, D., Pollak, T. A., McGuire, P., Fusar-Poli, P., Zandi, M. S., Lewis, G., \& David, A. S. (2020). Psychiatric and neuropsychiatric presentations associated with severe coronavirus infections: a systematic review and meta-analysis with comparison to the COVID-19 pandemic. The lancet. Psychiatry, 7(7), 611-627.

Rom, W. R., \& Garay, S. (1996). Tuberculosis. Boston, MA: Little, Brown and Company.

Russel, R. M. (2005). Vitamin and trace mineral deficiency and excess. In D. Kasper et al. (Eds.), Harrison's Principles and Practices of Internal Medicine (16 $\left.6^{\text {th }} \mathrm{ed}.\right)$. New York, NY: The McGraw-Hill Company, Inc.

Schreiber, W., \& Mathys, F. K. (1986). Infectio: Ansteckende Krankheiten in der Geschichte der Medizin. Basel, Switzerland: Edition Roche.

Teive, H. A. G., Sá, D., Silveira Neto, O., da Silveira, O., \& Werneck, L. C. (1999). Professor Antonio Austregésilo: O pioneiro da neurologia e do estudo dos distúrbios do movimento no Brasil. Arquivos de Neuro-Psiquiatria, 57 (3B), 898-902.

Tramont, E. C. (2005). Treponema pallidum (Syphilis). In L. Gerald, R. Mandell, D. Gordon Jr., \& John E. Bennett (Eds.), Principles and practice of infectious diseases ( $6^{\text {th }}$ ed., pp. 2768-2784). London, UK: Elsevier Churchill Livingstone.

Treanor, J. J. (2005). Influenzae Virus. In L. Gerald, R. Mandell, D. Gordon Jr., \& John E. Bennett (Eds.), Principles and practice of infectious diseases $\left(6^{\text {th }}\right.$ ed., pp. 2060-2085). London, UK: Elsevier Churchill Livingstone.

Tsai, T. F., Vaughn, D. W., \& Solomon, T. (2005). Flaviviruses (Yellow fever, Dengue, Dengue Hemorrhagic Fever, Japanese Encephalitis, West Nile Encephalitis, St. Louis Encephalitis, Tick-borne Encephalitis). In L. Gerald, R. Mandell, D. Gordon Jr., \& John E. Bennett (Eds.), Principles and practice of infectious diseases $\left(6^{\text {th }}\right.$ ed., pp. 1926-1950). London, UK: Elsevier Churchill Livingstone.

Uchôa, D. M. (1981). Algumas personalidades de destaque na psiquiatria brasileira. In Organização da psiquiatria no Brasil (pp. 77-82). São Paulo, SP: Sarvier.

\section{Resumos}

(On psychoses associated with infections in Brazil: 100 years of the psychopathological contribution by Antônio Austregésilo)

The present article analyzes the contribution of neurologist and neuropsychiatrist Antonio Austregésilo (1876-1960) for the psychopathological study and systematization of so-called infectious psychoses in Brazil. Based on Emil 
Kraepelin and using clinical observations on global and tropical infectious diseases, Austregésilo built detailed clinical knowledge and took part in the debate on etiology, specificities of causal factors and the course of the disease, which is located on the edge between infectious physical diseases and mental disorders.

Key words: Psychopathology, infectious psychoses, neurology, delirium, causality

(Sur les psychoses associées aux infections au Brésil: 100 ans de contribution psychopathologique de Antônio Austregésilo)

Cet article analyse la contribution du neurologue et neuropsychiatre Antonio Austregésilo (1876-1960) à l'étude psychopathologique et à la systématisation des psychoses dites infectieuses au Brésil. Basé sur Emil Kraepelin et en utilisant des observations cliniques sur les maladies infectieuses mondiales et tropicales, Austregésilo construit un savoir clinique détaillé et participe au débat sur l'étiologie, les spécificités des facteurs causals et le cours de la maladie, à la frontière entre les maladies physiques infectieuses et les troubles mentaux.

Mots clés: Psychopathologie, psychoses infectieuses, neurologie, délire, causalité.

(De las psicosis asociadas a infecciones en Brasil:1 00 años de la contribución psicopatológica de AntonioAustregésilo)

En el presente trabajo, analizamos la contribución del neurólogo y neuropsiquiatra Antonio Austregésilo (1876-1960) al estudio psicopatológico y a la sistematización de las llamadas psicosis infecciosas en Brasil. Basándose en Emil Kraepelin y utilizando observaciones clínicas sobre enfermedades infecciosas globales y tropicales, Austregésilo revela conocimientos clínicos detallados e interviene en el debate sobre la etiología, las especificidades de los factores causales y el curso de la enfermedad, en la frontera entre las enfermedades fisicas infecciosas y los trastornos mentales.

Palabras clave: Psicopatología, psicosis infecciosas, neurología, delirio, causalidad.

Citação/Citation: Dalgalarrondo, P., Moraes, M. J., Celeri, E. H. R. V., \& Santos Jr., A. dos (2020, setembro). Das psicoses associadas a infecções no Brasil: 100 anos da contribuição psicopatológica de Antônio Austregésilo. Revista Latinoamericana de Psicopatologia Fundamental, 23(3), 645-666. http://dx.doi.org/10.1590/1415-4714.2020v23n3p645.12.

Editora/Editor: Profa. Dra. Ana Maria R. G. Oda e Profa. Dra. Sonia Leite

Submetido/Submitted: 25.8.2020 / 8.25.2020 Aceito/Acepted: 27.8.2020 / 8.27.2020 


\section{ARTIGOS}

Copyright: (C) 2009 Associação Universitária de Pesquisa em Psicopatologia Fundamental/ University Association for Research in Fundamental Psychopathology. Este é um artigo de livre acesso, que permite uso irrestrito, distribuição e reprodução em qualquer meio, desde que o autor e a fonte sejam citados / This is an open-access article, which permits unrestricted use, distribution, and reproduction in any medium, provided the original authors and sources are credited.

Financiamento/Funding: Este trabalho não recebeu apoio / This work received no funding.

Conflito de interesses/Conflict of interest: Os autores declaram que não há conflito de interesses. / The authors declare that there is no conflict of interest.

\section{Paulo Dalgalarrondo}

Professor titular do Departamento de Psicologia Médica e Psiquiatria da Faculdade de Ciências Médicas da Universidade Estadual de Campinas - Unicamp (Campinas, SP, Br). pdalga@unicamp.br https://orcid.org/0000-0001-9870-6391

\section{Mônica Jacques de Moraes}

Médica infectologista da Unidade de Pesquisas Clínicas em HIV, Disciplina de Infectologia do Departamento de Clínica Médica e Professora do Programa de Pós-Graduação em Gerontologia da Faculdade de Ciências Médicas da Universidade Estadual de Campinas - Unicamp (Campinas, SP, Br); Membro do Comitê Assessor em Terapia Antirretroviral para Adultos e Adolescentes do Ministério da Saúde.

mojacques@terra.com.br

https://orcid.org/0000-0002-2918-3555

\section{Eloísa Helena Rubello Valler Celeri}

Professora Doutora do Departamento de Psicologia Médica e Psiquiatria da Faculdade de Ciências Médicas da Universidade Estadual de Campinas - Unicamp (Campinas, SP, Br). evaller@unicamp.br

https://orcid.org/0000-0001-9849-9214

\section{Amilton dos Santos Júnior}

Professor Doutor do Departamento de Psicologia Médica e Psiquiatria da Faculdade de Ciências Médicas da Universidade Estadual de Campinas - Unicamp (Campinas, SP, Br). amilton1983@yahoo.com.brou amilton@fcm.unicamp.br https://orcid.org/0000-0002-4328-4619

This is an open-access article, which permits unrestricted use, distribution, and reproduction in any medium for non-commercial purposes provided the original authors and sources are credited. 